\title{
THE WALTER AND ELIZA HALL INSTITUTE OF MEDICAL RESEARCH
}

\author{
G. J. V. Nossal, M.D., Ph.D., Director
}

The Walter and Eliza Hall Institute of Medical Research in Melbourne is not a recently established entity, nor has it undergone a sudden, profound conversion to molecular medicine, but is typical of a number of institutions that have made the switch in a gradual manner. Devoted as the Institute chiefly is to immunology and hemato-oncology, molecular biologic approaches have occupied its every nook and cranny. Moreover, as the Institute is determinedly a medical research institute rather than an institute of basic biology, the medical/clinical implications of the work, though never forced, are never far from our minds.

\section{HISTORY OF THE HALL INSTITUTE}

The Institute was born in 1915 as a child of The Melbourne (now The Royal Melbourne) Hospital and The University of Melbourne. A bequest from Mrs. Eliza Hall, the widow of Walter Hall, who made a fortune out of mining and grazing, provided initiating funding, but it is noteworthy that the Hall Trust never provided substantial funds. Today, Walter and Eliza Hall derive their immortality via $0.04 \%$ of our budget!

The Institute suffered an early blow when its first Director-Designate, Dr. G. C. Mathison, was mortally wounded at Gallipoli on May 9, 1915. For the rest of the war, the Institute served as host to the Commonwealth Serum Laboratories, and the first actual Director, Dr. S. W. Patterson, arrived from England only in 1919. He was an Australian physiologist and later gastroenterologist, who clearly was bitterly disappointed at the slender support from the Hall Trust. He departed in 1923, to be followed by Dr. C. H. Kellaway, Director from 1923 to 1944. Kellaway was a 34-year-old Australian physician/physiologist and a protégé of the great Sir Henry Dale. He

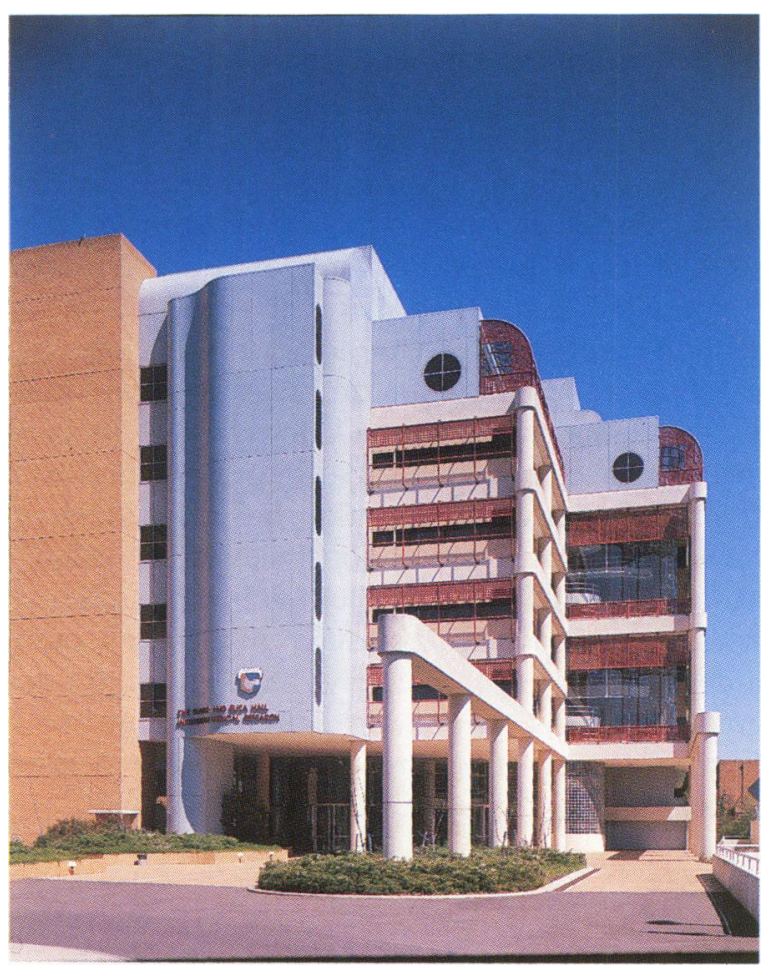

FIG. 1. The Walter and Eliza Hall Institute of Medical Research, Melbourne, Australia

proved to be an excellent leader and gradually built the Institute into the foremost center of medical research in Australia. His work on SRS-A, later discovered to represent the leukotrienes, and also on snake venoms and antivenenes, has stood the test of time.

Frank Macfarlane Burnet took over in 1944, Kellaway leaving him as a legacy a functional new building with three floors (physiology, biochemistry, and virology) to which Burnet soon added the Clinical Research Unit. Whereas Kellaway had encouraged a number of essentially independent lines of research, Burnet favored a much more focused approach. For a dozen years 
or so, the emphasis was on animal virology and particularly influenza. Then the pendulum swung towards cellular immunology and especially the exploration of the clonal selection theory of immunity. When I took over in 1965, the only person not involved in immunology was Donald Metcalf, who was attempting to understand the causes of leukemia and regarded himself more as a hematologist/pathologist.

In the developments of the last 30 years, I have attempted to draw the most out of the vision of my two great predecessors. Kellaway spotted human talent and encouraged its independent flowering. Burnet realized the importance of critical mass and teamwork. I decided we needed a broad central theme but not a narrowly restricted one. The word immunology should be a window, not a prison. Furthermore, we needed a much greater diversity of background skills and technologies, requiring the most up-to-date equipment. I was fortunate that Jerry Adams and Suzanne Cory came to join us in 1970 to set up a molecular biology laboratory. Over the quarter century that has elapsed, they have built up a tremendously effective group. Moreover, the many excellent graduate students whom they have trained have made their own independent impact. Many have gone on to great things elsewhere, but many have returned to the Institute and spread the message of molecular biology to all the laboratories.

\section{MOLECULAR MEDICINE IN THE HALL INSTITUTE, 1996}

The Institute comprises eight units, which are listed below though in many respects, this listing does not tell the full story. First, there is a great deal of inter-unit collaboration and collegiality, much of it of a highly informal nature not fully reflected in the publication record. Secondly, some units overlap considerably in their research interests, while others have offshoots which grew naturally out of the intellectual development of particular faculty members and which espouse new research goals.

The units are as follows:

\section{The Cellular Immunology Unit}

HEAD, PROFESSOR G. J. V. NOSSAL. A long-standing interest of this unit has been the physiology and molecular biology of the B lymphocyte. A recent thrust has been somatic hypermutation of immunoglobulin $\mathrm{V}$ genes in germinal centers. Two molecular biology laboratories are respectively working on the rel and related transcription factors, and the molecular regulation of apoptosis. Another offshoot works on the eph-like receptor tyrosine kinase family, particularly in relation to lymphoid malignancies. The largest "child" of this group is the Neuroimmunology Laboratory devoted to the role of growth factors in lineage determination in the nervous system.

\section{The Thymus Biology Unit}

HEAD, PROFESSOR J. F. A. P. MILLER. This unit has two main thrusts, namely mechanisms of tolerance induction in T lymphocytes, for the analysis of which a number of ingenious transgenic lines of mice have been developed, and genetic mechanisms in autoimmune diseases of humans and mice, particularly insulin-dependent diabetes.

\section{The Lymphocyte Differentiation Unit}

HEAD, DR. K. D. SHORTMAN. This unit has a proud history of achievement in sorting out developmental lineages within the thymus. The latest surprise is that a very immature population of cells with a characteristic phenotype can give rise within the thymus to $\mathrm{T}$ cells and dendritic cells. Furthermore, it appears there are two distinct types of dendritic cells, one more common in the thymus, another in lymph nodes. This Unit has a major commitment to the molecular biology of new cell surface molecules.

The above three units, being devoted to cellular and molecular immunology, in many respects constitute a large team.

\section{The Cancer Research Unit}

HEAD, PROFESSOR D. METCALF. This unit aims to understand how blood cell formation is controlled and how abnormalities in regulation lead to leukemia. It is famous for the discovery and development of the colony-stimulating factors, or CSFs. More recently, extensive work has been done on newer growth factors such as LIF, IL-11, Flk-ligand, and thrombopoietin. Receptors for growth factors are under intense investigation including via gene knock-out methods. In association with the Ludwig Institute and The Royal 
Melbourne Hospital, pioneering clinical trials of growth factors are under way.

\section{The Burnet Clinical Research Unit}

HEAD, PROFESSOR L. C. HARRISON This unit is devoted to human autoimmune diseases with special emphasis on insulin-dependent diabetes and rheumatoid arthritis. Immunological and genetic studies have markedly improved the capacity to diagnose pre-clinical diabetes, and antigen-based therapy for prevention are in the late planning stage. Molecular cloning of important auto-antigens is a long-standing interest of this unit, and a newer area of endeavour is the search for growth factors for precursors of insulin-secreting cells and genes which may developmentally regulate $\beta$ cell differentiation. Transgenic and gene knock-out techniques are being used to understand better the pathogenesis of the islet lesion. Mechanisms of cell proliferation and cell death in rheumatoid synovium are being studied by new techniques.

\section{The Molecular Biology Unit}

JOINT HEADS, PROFESSOR J. M. ADAMS AND PROFESSOR S. CORY The central problem being addressed by this unit is how genetic accidents can cause cancer and how genes control development, differentiation, survival, and death of cells. Genetically engineered mice are a prominent feature of the work. Oncogene cooperativity has been a longstanding interest, a recent example being the drastic combined effects of ablation of $\mathrm{p} 53$ and transgenic induction of $c-m y c$. Other studies involve searching for the role of "master genes" in murine development. Three homeobox genes of vital interest are Hlx, necessary for proper development of the liver and gut; Nkx 2.5, knock-out of which causes cardiac defects; and Oct-2, disruption of which upsets $B$ cell proliferation leading to immunodeficiency. The role of $b c l-2, k i z-1$ and FGF in development of the nervous system represents another facet of this unit's work.

\section{Immunoparasitology Unit}

HEAD, PROFESSOR G. V. BROWN A major goal of this unit is the development of anti-parasite vaccines. The chief targets are Plasmodium falciparum malaria, where Phase I trials of a number of recombinant vaccine candidate molecules have been undertaken; and leishmaniasis, where a polymorphic family of membrane proteins, the PSA-2 complex, is being characterized. The role of malarial glycosyl-phosphatidylinositol phospholipids in malarial pathology is being pursued. Another important facet is the biochemical and genetic basis of drug resistance in malaria. A newer development is the establishment of the Mammalian Genetics Laboratory. This is working not only on the genetics of susceptibility of mice to malaria and leishmania, but also of humans to a variety of diseases including glaucoma and familial glomerulopathy. This unit is also the Melbourne node of the Wellcome Trust malaria genome project, which has already produced YAC contig maps of most of four different malarial chromosomes.

\section{Transplantation Unit}

HEAD, DR. T. E. MANDEL The chief focal point of this unit is transplantation of pancreatic islet cells for the treatment of insulin-dependent diabetes with a further emerging interest in regeneration of insulin-producing $\beta$ cells from putative precursor cells in pancreatic ducts. A favored approach to transplantation is the use of fetal pig pro-islets that have been precultured in a miniorgan culture. This treatment diminishes but does not eliminate the induction of transplant rejection. Immunosuppressive regimes have been worked out that allow the cure of murine diabetes, but are presently too severe for human use; thus, effort is being directed at finding safer and more effective forms of immunoablative therapy.

\section{THE SPECIAL CACHET:}

\section{AN AUSTRALIAN TEAM WITH AN INTERNATIONAL FLAVOR}

What aspects distinguish the Hall Institute from other organizations of similar size? At 320 people, including 50 graduate students, and with an annual budget of (A)\$23 million ([US]\$17 million), it is large by Australian standards, but only medium-sized by world standards, and quite small by US standards. Much of its flavor derives from the realization that, to be competitive in international medical science from such a remote geographic base, extra effort has to be put into making the whole greater than the sum of the parts. A strong collegiality, amounting almost to a family atmosphere, is consciously fostered. The 
obligate twice a day "tea" breaks, a web of lunchtime seminars, a diverse array of social occasions, and a building layout favoring interactions are among the many tactics used. We attach supreme importance to shared specialist laboratories such as protein structure, flow systems, and computer science; and to shared technical and administrative services. We also reach out to form networks giving us access to advanced skills such as X-ray crystallography, NMR, and computer modeling. We cherish our clinical links with great care, especially those with The Royal Melbourne Hospital. We welcome, at any one time, about 20 or so international scholars, chiefly postdoctoral fellows, but also quite a few sabbatical leave visitors, and our faculty includes many born elsewhere than Australia. A real dynamism comes from the fact that we are a great training ground for Australian professors and for quite a few scientists who move to the United States or the United Kingdom. A certain tenuous security comes from an endowment of about (A) $\$ 50$ million carefully built up over the decades.

On the June 4, 1996, the Hall Institute enters a new era, with the retirement of Don Metcalf, Jacques Miller, and myself. As this article goes to press, the Board of the Institute is in the midst of choosing the next Director ${ }^{1}$. Because of my knowledge of the present staff, both experienced and young, and my confidence in the wisdom of the Board, I have no doubt that the Institute will go from strength to strength towards the millenium.

${ }^{1}$ Professor Suzanne Cory has since been chosen as the next Director of the Walter and Eliza Hall Institute of Medical Research. 